\title{
Interactive comment on "The Quick Assessment Model of Casualties for Asia based on the Vulnerability of Earthquake" by Yue Zhang et al.
}

\section{Anonymous Referee \#2}

Received and published: 5 March 2018

\section{GENERAL COMMENTS}

Modelling casualties caused by earthquakes is an essential contribution both to emergency management and planning. In particular, the rapid assessment of casualties after an earthquake is of great importance for post-disaster response interventions. Due to the large uncertainty in casualties estimates, this topic requires constant updating, in data and models, as it is addressed in this paper.

However, for several reasons, the paper would need major improvements to be acceptable for publication:

1. The paper is written in English language of poor quality and sometimes, it is difficult to distinguish throughout the text whether we are dealing with poor English or with not

Printer-friendly version

Discussion paper 
clearly stated concepts.

2. The title is not easy understand: "THE quick assessment model .... based on the VULNERABILITY OF EARTHQUAKE".: a. I suggest to substitute "The [...] model" by "A [...] model", since there is not a single model of casualties for Asia known by the readers. b. What does it mean the "vulnerability of earthquake"? Do earthquakes have vulnerability?

3. It is recognised that the number of earthquake shaking deaths is closely related to the number of buildings collapse (So \& Spence, 2012). On the other hand, the lack of detailed knowledge of the building stock in different regions of the world leads to the adoption of more simplified models for casualties' estimation, relating fatality rates, to exposed population and to shaking intensity levels. However, the authors fail to justify, early in their work, the adoption of such a simplified model. Besides, more than once, the authors refer to an "empirical relationship between the MAGNITUDE of an earthquake event and the CASUALTY RATE caused by it" (e.g. pp 1, line 10, or pp 3 line 15 , pp. 5 line 10, etc.). The explanatory power of such a model should be very reduced, since the distance from the earthquake source to the affected population is not mentioned. However, latter it is possible to understand that another variable, the epicentre location, is also included in the model in order to estimate the "radius of the earthquake". The inaccurate description of the model proposed (casualty as a function of magnitude) should be avoided and corrected everywhere in the paper.

4. The Introduction of the manuscript is well organized according to a typical structure of a scientific paper, i.e., from general to the particular, providing the reader with a setting or context of the problem to be investigated, presenting more specific statements about the aspects of the problem already studied by other researchers, indicating the need for more investigation and giving the purpose/objectives of the study (Cargill and 'Connor, 2009). The research gaps the authors want to fill with the present study are (i) published international disaster casualty systems were not "developed specifically for Asian countries" and (ii) that those systems "would" provide a "discrepancy between

Printer-friendly version Discussion paper (c) (i) 
simulated and actual intensity". Yet, the existence of that discrepancy is an hypothesis that was not really investigated and no solution for it was provided in the paper. It is not clear in the paper and it is highly unlikely that the formula used to determine the "range of earthquake affected area" (pp. 6, line 2) was specifically developed for Asian countries. Moreover, in page 7, lines 11 an 12, the authors criticise the accuracy of the method saying that "The radius obtained by this method might be too large.". In conclusion, the authors did not present any advantage of using a very simplified model to estimate casualty rates instead of taking adequate attenuation laws of ground motions to evaluate intensity levels, damage and death tolls, as it is usually presented in literature

5. The Asian Earthquake Database that was developed in this study has data on the "Death Toll" and "Number of Injuries", but the proposed casualty ratio model aggregates deaths and injuries. This simplification should be avoided or well justified.

6. The number of references are reduced, important references related to earthquake casualty estimation are missing.

\section{SPECIFIC COMMENTS}

1. Introduction, pp. 1 line 28: the authors claim that "rapid" earthquake casualty modelling is needed for the "vulnerability assessment of earthquake disaster", however for such situation there is no urgency in estimating casualties and would be advisable to plan prevention strategies based on more reliable risk approaches, rather than on quick assessment estimates.

2. The meaning of "radius R for earthquakes" (pp. 5, line 25) needs to be clarified.

3. Pp. 7 , line 20 , casualty rate is defined to the ratio between injuries and deaths, whereas in equation 1 , the casualty ratio is defined as the sum of deaths and injuries to physical exposure. The definitions are not consistent and must be clarified.

4. Pp.7 line 22: the authors state that "if the casualty rate is larger, it means that the

Printer-friendly version

Discussion paper

Interactive

comment

\section{(n)}


seismic capacity is higher and the vulnerability of the population is smaller." If casualty rate is defined according to equation 1 , I would expect the opposite of the authors statement, i.e., if the casualty rate is larger the vulnerability of the population is larger. Moreover, there is no definition on what seismic capacity is.

5. Pp. 7, lines 25 to 32 - The authors say that "Iran issued seismic codes for buildings, which require people to reinforce buildings with poor seismic performance". The authors describe the impact of two earthquakes after the codes being in force, but did not investigate whether code provisions were applied in practice.

6. Pp. 9 lines 6 to 10 - the justification to use a very simplified model should appear in the beginning of the paper.

\section{TECHNICAL CORRECTIONS}

1. In page 5 the idea "is often in regions where shaking intensity reaches $\mathrm{VI}$ or greater that casualties occur" is repeated twice (lines 18 and 24).

2. In table 1 the values of the Per Capita GDP are not exactly equal to the values of GDP divided by the population.

3. The ranking order of the groups of countries in table 1,2 and 3 is only explained in the discussion (pp. 7), whereas these tables are mentioned in the text quite earlier.

4. Pp. 7, lines 15 to 18 - the authors mention "under 6" and "above 7.75". The word magnitude is missing.

\section{REFERENCES}

Cargill M. and O'Connor, P. (2009) "Writing Scientific Research Articles. Strategy and Steps" Wiley-Blackwell. Jonh Wiley \& Sons. Ltd.

So, E. and Spence, R. "Estimating shaking-induced casualties and building damage for global earthquake events: a proposed modelling approach" Bull. Earthquake Eng. DOI 10.1007/s10518-012-9373-8 
Interactive comment on Nat. Hazards Earth Syst. Sci. Discuss., https://doi.org/10.5194/nhess2018-21, 2018.
NHESSD

Interactive

comment 